\title{
The dynamics of leverage in a demand-driven model with heterogeneous firms*
}

\author{
Laura Carvalho, Corrado Di Guilmi \\ Department of Economics - University of Sao Paulo, Brazil. \\ Business School - University of Technology, Sydney. Australia.
}

\begin{abstract}
This paper introduces heterogeneous microeconomic behavior into a demand-driven macroeconomic model, in order to study the joint dynamics of leverage, income distribution and economic growth. The distinctive feature is in that the aggregation of heterogeneous agents is not only performed numerically, as in traditional agent-based models, but also by means of an innovative analytical methodology, originally developed in statistical mechanics and recently imported into macroeconomics. By analytically identifying the links between firms-level variables and aggregate quantities, the paper contributes toward a reformulation of the Minskyan formal analysis that explicitly considers the microeconomic factors. The steady-state and stability properties of the system also provide additional insights on the role of behavioral and size heterogeneity of firms for the stocks of aggregate leverage and capital.
\end{abstract}

\section{Resumo}

Este artigo introduz comportamento microeconômico heterogêneo num modelo macroeconômico liderado pela demanda, com o intuito de estudar a dinâmica conjunta de alavancagem, distribuição de renda e crescimento econômico. A característica que distingue o modelo é o fato da agregação de agentes heterogêneos não ser feita somente de forma numérica, como tradicionalmente em modelos "agent-based", mas também por meio de uma metodologia analítica inovadora, originalmente desenvolvida em mecânica estatística e recentemente importada para a macroeconomia. Através da identificação analítica das conexões entre variáveis ao nível da firma e quantidades agregadas, o artigo contribui no sentido de uma reformulação da análise formal Minskyana que considera explicitamente fatores microeconômicos. O estado estacionário e as propriedades de estabilidade do sistema proveem novas perspectivas sobre o papel da heterogeneidade comportamental e de tamanho das firmas para os estoques de capital e alavancagem agregados.

Keywords: Financial Instability Hypothesis, aggregate demand, leverage, heterogeneous agents

Palavras-chave: Hipótese da Instabilidade Financeira, demanda agregada, alavancagem, agentes heterogêneos.

JEL classification: E16, E32, G01

Área 8 ANPEC: Microeconomia, Métodos Quantitativos e Finanças.

${ }^{*}$ We thank André Diniz for the superb research assistance. Financial support by the Institute for New Economic Thinking is gratefully acknowledged. The usual disclaimers apply.

${ }^{\diamond}$ Corresponding author: Corrado Di Guilmi. University of Technology, Sydney - PO Box 123, Broadway, NSW 2007, Australia. Ph.: +61295147743, Fax: +61295147711. E-mail: corrado.diguilmi@uts.edu.au. 


\section{Introduction}

The 2008 financial turmoil itself, and the process of de-leveraging by the private sector observed in the following years, have drawn the attention to the crucial role of credit as a factor leading both to the instability of the system and to a strengthening of real-financial linkages in the economy. This view, which was central to the work of Hyman Minsky, is also supported by the vast historical evidence presented in Schularick and Taylor (2012), which highlights that credit booms tend to be followed by deeper recessions when compared to other financial crises episodes.

A formal investigation of these phenomena from a Minskyan standpoint requires the integration of the financial and economic systems in a demand-driven macroeconomic model. A seminal formalization of a Minsky crisis generated by self-fulfilling expectations was made by Taylor and O'Connell (1985) using a Kaleckian model, but without dealing explicitly with the role of debt. An alternative, which has received renewed attention after the crisis Khalil and Kinsella (2011); Bezemer (2010), builds on the traditions of Tobin (1969) and Godley and Lavoie (2007) to take into account all flows of income between sectors in the economy, as well as their accumulation into financial and tangible assets in a Keynesian setup. Besides allowing for formal Minskyan analyses of corporate debt and financial fragility (Dos Santos, 2005), the so-called StockFlow Consistent (SFC) models have recently been used to study the macroeconomic effects of shareholder value orientation and financialization (Van Treeck, 2009), household debt accumulation (Kim and Isaac, 2010), and other related issues.

The traditional limitation of this type of models, however, is that of dealing with economic behavior only in aggregative terms, thus excluding the heterogeneity of agents as a source of financial instability. The relevance of a microeconomic analysis in modeling financial fragility was stressed by Minsky himself ${ }^{1}$. It is thus for understanding the economy as an "out-of-equilibrium" system while allowing for heterogeneous microeconomic behavior (Delli Gatti et al., 2005, 2010), that the literature based on the so-called agent-based models (ABMs) has proven to be so useful for the analysis of financial instability. Nevertheless, for using a fully bottom-up approach, this type of models often lack a clear macroeconomic closure and are hard to connect to other macro analyses.

The starting point of this paper is to see agent-based, SFC and, more generally, Keynesian-Kaleckian macroeconomic approaches as complementary in their understanding of the crucial role of real-financial linkages for the instability of the economic system, as well as its macroeconomic dynamics 2 . Moreover, we aim to contribute in filling what we consider to be a weakness in both the SFC and ABM approaches, namely its full reliance on numerical and computational solutions. ${ }^{3}$ In order to provide a few analytical insights that will add to the numerical simulations of the model, we perform an aggregation of heterogeneous agents by means of an innovative analytical methodology originally developed in statistical mechanics and recently imported into macroeconomics (see Aoki and Yoshikawa, 2006, Di Guilmi, 2008, Foley, 1994, Weidlich, 2000, among others). This modeling approach builds from the idea that, as the economy is populated by a very large number of dissimilar agents, an analytical model cannot keep track of the conditions of every single agent at each point in time. As Aoki and Yoshikawa (2006) remark: "the point is that precise behavior of each agent is irrelevant. Rather we need to recognize that microeconomic behavior is fundamentally stochastic." Therefore, a

\footnotetext{
1"An ultimate reality in a capitalist economy is the set of interrelated balance sheets among the various units" (Minsky, 2008, 116). Taylor and O'Connell (1985) remark that "shifts of firms among classes as the economy evolves in historical time underlie much of its cyclical behavior. This detail is rich and illuminating but beyond the reach of mere algebra".

${ }^{2}$ Such complementarities are clear in Godin and Kinsella (2012), which combines the two approaches in a study of the interaction of banks and firms in the leverage cycle. A dynamic micro-macro analysis is also developed in the work by Dosi et al. (2013), which builds an agent-based Keynesian model for the study of interactions between income distribution and monetary and fiscal policies.

${ }^{3}$ The main problem with solving these models only numerically is that model results are usually very sensitive to parameter configurations, making it very difficult to establish general relationships between macro and micro-variables, as well as causality links within the system.
} 
microfounded analytical model should look at how many agents are in a certain condition, rather than at which agents, and represent their evolution in probabilistic terms. This approach is particularly suitable to microfound macroeconomic models, since it is able to endogenously derive the macro-equations and the dynamics of flows from the microeconomic behavioral rules, without imposing ad-hoc constraints.

Hence, the contributions of this paper are basically three. The first is mainly methodological, and consists in the integration of the numerical and analytical solutions of an agent-based model, as done, for instance, in Chiarella and Di Guilmi (2011). Besides helping us open the "black box" of the simulations, the analytical approach allows for a few generalizations and a better assessment of the role of heterogeneity in levels and dimensions in relation to a more homogeneous microeconomic setup.

The second contribution, also methodological, concerns the innovative approach to the microfoundation of stock-flow consistent modeling. The macro-equations of the aggregate model are here generated endogenously in a bottom-up approach, starting from the behavioral equation for agents. Consequently, the steady-state analysis is able to assess the impact of the balance sheet structures of firms on the macroeconomy.

The third contribution is to explore micro and macroeconomic aspects leading to the emergence of shortrun fluctuations and long-run instability of the economic system. In particular, the paper shows how the diverse financial structures of firms can determine the evolution of the economy, as stressed in Minsky's narrative. As the objective is not to fully represent the behavior of any particular economy over time, but rather to provide a few methodological and theoretical insights for the analysis of leverage and financial instability, the model we present is particularly simple and stylized, but it is still able to point toward the usefulness of the method for more realistic settings.

The paper will be structured as follows. Section 2 presents the structure of the agent-based model. Results of the numerical simulations are then illustrated in section 3. Section 4 specifies the dynamics of firms' transition between states, as well as the mean-field approximation procedure we use for the analytical solution of the model. In Section 5, we perform steady-state and stability analyses of the system of differential equations for the joint evolution of firms' aggregate leverage and the proportion of firms in different financial states. Section 6 concludes the paper and points toward future developments.

\section{The model}

The economy described in this paper is composed by firms, households and a financial sector. Following Kalecki (1971), firms are assumed to set the price as a mark-up on the unit cost of labor, while holding excess capacity 4. The mark-up, and hence the functional distribution of income between wages and profits, will be assumed to (exogenously) depend on the degree of industrial concentration and the relative bargaining power of workers and capitalists in the labor market. The model is demand-driven in nature: output is always below potential, which allows for investment behavior to be determined independently from savings. The degree of capacity utilization of firms, which depends on the quantity they sell in each period, will take the adjusting role for the macroeconomic equilibrium in the goods market.

Firms are divided into two classes and may switch between them. While hedge firms pay all their interest out of gross profits, speculative firms' profits are lower than their financial commitments in the current period 5. The method proposed in Section 5 will allow the share of firms in each class to affect aggregate leverage dynamics. There is no microfoundation for the household sector, which is treated as an aggregate for simplicity. Their income is composed of wages and a component of profits distributed by firms. Households accumulate their entire stock of wealth in the form of money deposits.

\footnotetext{
${ }^{4}$ See Rowthorn (1982), Dutt (1984) and Taylor (1985) for early neo-Kaleckian models in this tradition.

${ }^{5}$ In the Mynskian terminology, Ponzi agents are distinguished from speculative agents for their income is never sufficient to make interest payments, requiring new borrowing at every period. This distinction will not be made here for simplification purposes.
} 
Finally, the financial sector is also considered as an aggregate: its basic role is to provide loans, hence holding debt (or firm bonds) as an asset and to create money deposits endogenously as liabilities, while setting an exogenous interest rate.

\subsection{Firms}

A single firm is identified by the superscript $j$, while its state (speculative or hedge) by the subscript $z=1,2$. Firm level variables are indicated by small letters while aggregate while variables are represented by capital letters. Thus when a variable is written as $x_{1}^{j}$, it refers to the firm $j$ belonging to state 1 . A lower case variable with only the subscript, $x_{1}$, indicates the mean-field value, which, as detailed in section 4 below, is a single value that replaces the vector of observations in each group. Symbols without superscript or subscript refer to aggregate variables. The numbers of firms in each group are indicated by $N_{1}$ and $N_{2}$. In a simplification of the Minskyan terminology, we define two classes of firms, depending on the sign of their retained profits $a^{j}$, here defined as the difference between gross profits and interest payments:

- $\mathbf{z}=1$ : speculative firms, whose gross profits in the current period are less than sufficient to pay interest on accumulated debt, requiring a new increase in debt.

$$
a_{t}^{j}<0
$$

- $\quad \mathbf{z}=$ 2: hedge firms, whose profits in the current period are more than sufficient to pay interest on accumulated debt.

$$
a_{t}^{j} \geq 0
$$

The investment function for the firm $j$ is given by ${ }^{6}$

$$
i_{z, t}^{j}=i_{0} K_{z, t-1}^{j}+\left(\alpha_{z} \pi+\beta\right) p q_{t-1}^{j}-\lambda b_{t-1}^{j}
$$

where $q^{j}$ is the quantity sold by the firm, $\pi$ is the share of profits in output, $p$ is the final good's price, $b$ is the firm's outstanding debt and $i_{0}, \alpha, \beta, \lambda \geq 0$. This specification is the equivalent in levels to the standard neo-Kaleckian specification in which the gross percentage change in capital before depreciation is a positive function of the gross profit rate and the degree of capacity utilization 7

The positive effect of the profit rate on investment decisions can be justified based on two different channels: (i) it determines the level of internal finance available for investment, and (ii) it gives the return on productive capital, thus providing an incentive for firms to invest. When it comes to the magnitude of the parameter $\alpha$, the formulation recalls the one in Delli Gatti et al. (1993), where the sensitivity to internal finance analytically devices the Minskyan borrower's and lender's risk. Following Fazzari et al.(1988) and Delli Gatti et al. (1993), we assume that $\alpha_{1}>\alpha_{2}$, that is speculative firms are more sensitive to internal finance as they face the risk of bankruptcy and change their behavior in order to minimize it.

\footnotetext{
${ }^{6}$ For computational needs, in the multi-agent simulations we consider a sequential economy that evolves in discrete time, and the model will be presented accordingly.

${ }^{7}$ When technology exhibits fixed coefficients, it is possible to define the potential output only as a function of capital so that

$$
\bar{q}_{t}^{j}=1 / \gamma k_{t}^{j}
$$

where the inverse of capital productivity $\gamma$ is a constant parameter, which can be normalized to one for simplicity. The degree of capacity utilization $u^{j}$ of each firm, defined as the ratio of actual output $q^{j}$ sold by the firm to potential output $\bar{q}^{j}$ can thus be approximated to the actual output-to-capital ratio $u=\frac{q}{k}$.
} 
Investment decisions to expand the available capital stock also respond positively to firms' sales, as higher demand and a higher use of the existing capacity cause firms to expand their desired productive capacity and potential output. Finally, the third term in 3 allows the level of outstanding debt to inhibit investment decisions, as firms face higher balance sheet constraints. Equation (3) thus involves three factors: a micro-effect $\left(b^{j}\right)$, a meso-effect $\left(\alpha_{z}\right)$ and a variable combining micro and macro effects $\left(q^{j}\right)$.

The quantity actually sold by a firm is subject to a preferential attachment shock. Total demand $p Q(t)$ is determined as the macroeconomic level from aggregate investment and consumption, but its distribution among firms needs to be identified. We assume that this distribution is partially stochastic. In particular, demand is allocated based on the relative of size of firms (proxied by their stock of capital), to which a stochastic idiosyncratic shock $s$ is added. The expected market share of firm $j$ is hence:

$$
\mathbb{E}\left[q_{t}^{j}\right]=Q_{t} \frac{k_{t}^{j}}{K_{t}},
$$

where $Q_{t}$ is the total demand, given by the consumption of managers and wage earners, and $K$ represents the aggregate capital for the whole economy. Defining $\tilde{s}$ as a uniformly distributed stochastic variable with $\mathbb{E}[\tilde{s}]=0$, we set

$$
s_{t}^{j}=\tilde{s}_{t}^{j}\left[1-\frac{k_{t}^{j}}{K_{t}}\right]
$$

in order for $\sum^{N} q^{j}=Q$. Accordingly the quantity actually sold by the single firm is

$$
q_{t}^{j}=\mathbb{E}\left[q_{t}^{j}\right]\left[1+s_{t}^{j}\right]
$$

Firms will set prices in oligopolistic markets by applying a mark-up over unit labor costs:

$$
p=(1+\mu) \frac{w}{\xi} .
$$

where $\mu$ is the mark-up rate, $w$ is the nominal wage and $\xi=Q / L$ is labor productivity.

With $\mu$ taken as a parameter, the mark-up rate is constant and the labor share of output $\Psi$ is also given exogenously from:

$$
\Psi=\frac{w}{p} \frac{1}{\eta}=\frac{1}{1+\mu}
$$

The gross profit share of aggregate output $\Pi$ will then be given by

$$
\Pi=1-\Psi=\frac{\mu}{1+\mu}
$$

As previously described, each firms' retained profits are computed as the difference between its gross profits and the net interest it pays on debt, at an exogenous interest rate $\bar{i}$. Since the flow of gross profits is given by a constant share $\Pi$ of each firms' output from the mark-up rule, retained profits can be expressed as:

$$
a_{t}^{j}=\Pi p q_{t}^{j}-\bar{i} b_{t-1}^{j}
$$

A firm will be assumed to fail if $b^{j} / k^{j} \geq c$, where $c$ is set as a positive constant. The probability for a bankrupted firm of being replaced is modeled as directly proportional to the performance of the economy in the previous period.

The increase in the stock of debt in the case of hedge firms will only occur when desired investment $i^{j}>a^{j}$, which requires firms to seek external finance for capital accumulation. Whenever $a^{j}>i^{j}$, firms will (partially or totally) repay their stock of debt and distribute any remaining profits to managers. 
Hence, the law of motion of firms' bonds when $a_{t}^{j}<i_{t}^{j}+b_{t-1}^{j}$ can be written as:

$$
\Delta b^{j}=i_{t}^{j}-a_{t}^{j}
$$

Whenever $a_{t}^{j} \geq i_{t}^{j}+b_{t-1}^{j}$, the previous stock of debt is entirely repaid, so that

$$
\Delta b^{j}=-b_{t-1}^{j}
$$

and the remainder $\Theta_{t}^{j}=a_{t}^{j}-i_{t}^{j}-b_{t-1}^{j} \geq 0$ is distributed to firms' managers (households), as will be described in subsection 2.2 .

\subsection{The household sector}

As described in the previous subsection, workers earn wages $w$ which add up to a constant share $\Psi$ of total output $Q$, and managers receive an amount $\Theta=\Sigma_{j} \Theta$ from firms' excess profits.

Households' total disposable income $Y$ is composed by wage and profit earnings:

$$
Y_{t}=\Psi p Q_{t}+\Theta_{t}
$$

Households' wealth is accumulated as an effect of savings $S$ in the form of money deposits $M$,

$$
\Delta W_{t}=\Delta M_{t}=S_{t}
$$

where savings $S$ are defined as the difference between households' disposable income and consumption levels $S_{t}=Y_{t}-C_{t}$.

Finally, consumption spending will be assumed to be a fixed proportion of disposable income and wealth, as in standard in SFC models (Godley and Lavoie, 2007). We will further assume that the propensity to consume out of wages is different (higher) than the propensity to consume out of distributed profits $\Theta=\sum_{j} \Theta^{j}$. The hypothesis of differential savings among income groups or social classes have been a key feature in neoKaleckian models since Kaldor (1955-1956) and Kalecki (1971).

$$
C_{t}=\left(1-s_{\Psi}\right) \Psi p Q_{t}+\left(1-s_{\Pi}\right) \Theta_{t}+(1-\sigma) W_{t-1}
$$

where $0 \leq s_{\Psi}, s_{\Pi}, \sigma<1$ and $\sigma$ are the propensities to save out of wages, distributed profits and wealth, respectively.

\subsection{The financial sector}

The financial sector is considered as an aggregate. It gives loans to firms, hence holding bonds as an asset, and creates money deposits endogenously. It charges an exogenous interest rate $\bar{i}$ on bank loans.

Since money deposits are assumed to earn no interest, net interest payments by firms allow the financial intermediary to accumulate net worth $\Omega_{b}$ according to:

$$
\Delta \Omega_{t}^{b}=\bar{i} B_{t-1}
$$




\subsection{Goods market equilibrium}

As the model is demand-driven, total output $Q$ adjusts to the sum of aggregate consumption $C$, from equation (16), and investment $I$.

$$
p Q_{t}=(1-s \Psi) \Psi p Q_{t}+\left(1-s_{\Pi}\right) \Theta_{t}+(1-\sigma) W_{t-1}+I_{t}
$$

As it is not possible to establish analytically how many hedge firms fall in the sub-category in which retained profits are more than sufficient to repay the total stock of debt, and thus the amount of profits that are distributed to managers, we will assume hereafter that the propensity to consume out of profits is zero $\left(s_{\Pi}=1\right)$ for simplicity. ${ }^{8}$

Solving for $p Q_{t}$ and substituting $\Psi$ from expression (9) yields

$$
p Q_{t}=\frac{1+\mu}{\mu+s_{\Psi}}\left[I_{t}+(1-\sigma) W_{t-1}\right]
$$

Section 5 will specify the dynamics of the number of firms in each state $N_{z}$, as well as the mean-field value for each macro-variable within the sub-population of speculative or hedge firms. Using equation (3) and following this notation, the aggregate level of investment $I_{t}$ in (18) can be written as:

$$
I_{t}=N_{1}\left[\left(\alpha_{1} \Pi+\beta\right) p q_{1, t-1}-\lambda b_{1, t-1}\right]+N_{2}\left[\left(\alpha_{2} \Pi+\beta\right) p q_{2, t-1}-\lambda b_{2, t-1}\right]
$$

\section{Numerical simulations}

We run numerical simulations of the above described agent-based model in Matlab. Figure 1 displays the simulation results for a single run: a cyclical pattern arises from this simple setup in line with the Minskyan characterization of the business cycle. In other words, the system goes through periods of debt-fueled booms, followed by busts triggered by firms' deleveraging and bankruptcies. During expansions, the share of speculative units increases together with aggregate leverage. At the peak of the cycle, the amount of debt becomes unsustainable and heavily leveraged firms start reducing investment, while financially distressed speculative firms default. The decline in aggregate demand only stops when firms' debt is small enough for investment to recover. The economy does not display any growth trend, given that technology and labor productivity are constant.

Despite the fact that fluctuations are perhaps too regular to be compared with a real economy, the model mimics the empirically observed pro-cyclicality of business debt and profits, as well as a few other regularities. First, Monte Carlo replications of the model yield a realistic value of 4 for the ratio between the variance of investment and the variance of consumption. The autocorrelation coefficients of output and investment are both equal to 0.89 over 50 Monte Carlo replications, being comparable to estimates in the literature for de-trended series. Second, the distribution of variations of output from period to period can be well fitted by a Weibull, in line with the evidence presented in Di Guilmi et al. (2005). Third, the distribution of firms is right-skewed according to different proxies of their size (capital, debt and profits), as also empirically detected.

The sensitivity of the agent-based model to parameter configurations was tested by means of Monte Carlo simulations. The parameters $\alpha_{1}, \beta, \delta, \mu, \lambda$ and $\bar{i}$ are varied within a given interval and for each value we run 1,000 replications, so as to make sure that results are not affected by the particular random seed of a single run. The intervals of variations we use are: $\alpha_{1} \in[0.2,0.45], \beta \in[0.05,0.35], \delta \in[0.025,0.15], \mu \in[0.3,0.7], \lambda \in$ $[0.01,0.13]$ and $\bar{i} \in[0.05,0.3]]^{9}$

\footnotetext{
${ }^{8}$ In a more complete model, the distribution of profits to managers could be replaced by share buybacks by firms, for instance, and would also not enter the determination of aggregate demand.

${ }^{9}$ The other parameters are set as in the benchmark scenario, with the exception of $c=3$, which smoothes the cycle without qualitatively affecting the results.
} 
Results of Monte Carlo simulations for $\alpha_{1}$ (figure 2a) allow for a numerical assessment of the role of behavioral heterogeneity, considering equation (3) and the fact that $\alpha_{2}$ is kept constant at 0.2 . Not surprisingly, an increase in $\alpha_{1}$, the sensitivity of speculative firms' investment to internal funds, reduces the degree of financial fragility of the system, as it lowers the share of speculative firms and the debt-to-GDP ratio. However the debt-to-capital ratio is slightly increasing in $\alpha_{1}$ for both speculative and hedge firms, and hence in aggregate terms, implying that the rate of accumulation of debt is faster than the accumulation of capital in these scenarios. Similar results are obtained from an increase in $\beta$, the sensitivity of investment to demand, but in this case the increase in the aggregate debt-to-capital ratio is more dramatic, due to the rise in speculative firms' leverage.

The results for a raise in the interest rate $\bar{i}$ (Figure 2b) show that a higher rate raises the bankruptcy ratio and, consequently, increases aggregate demand, while slowing down the accumulation of debt. This puzzling result can be explained both through the lower negative component in the investment function (3), due to lower debt in the system, and through the higher share of speculative firms, which have a higher sensitivity to internal resources and therefore are expected to invest more, ceteris paribus. At a first sight, the results seem to support a lean-against-the-wind type of policy, but only if one neglects the increase in volatility and the higher frequency and magnitude of fluctuations that are generated in the system.

In order to test the role of the firms' demography in determining this result, we run a different set of Monte Carlo simulations in which the maximum debt-to-capital ratio is increased to $c=25$, so that all bankrupted firms are immediately replaced by new ones 10 . In this setting, aggregate debt and the debt-to-capital ratio are increasing in $\bar{i}$ and almost all firms are speculative. Hence, results for aggregate demand and the debt-tooutput ratio can thus be seen as consequence of the assumption of a constant number of firms $N$ throughout the simulations.

An increase in $\lambda$ implies a greater sensitivity of firms' investment to their outstanding debt, or a higher degree of risk-aversion. Debt and debt-to-capital ratios are lower for higher $\lambda$ (figure also available upon request), while debt-to-output ratios increase, due the lower level of aggregate demand.

An increase in the profit share of output, as generated by a larger mark-up $\mu$, reduces aggregate demand, aggregate leverage and the proportion of speculative firms in the economy. These firms display a higher average debt-to-output ratio, but a lower debt-to-capital ratio, as they invest more due to higher profits, but sell less due to lower aggregate demand. At the aggregate level, however, the increase in profits more than compensates for the decline in aggregate demand, leading to lower aggregate leverage. The lower level of aggregate demand also inhibits investment decisions, partially offsetting the positive effect of higher profitability on capital accumulation. Overall, the debt-to-capital ratio decreases both for speculative firms and at the aggregate level.

Finally, a higher rate of depreciation of capital has a proportionally larger impact on debt, via bankruptcy, than on capital and demand, causing a reduction in the overall leverage. In contrast, the debt-to-capital ratio of speculative firms is increasing in $\delta 11$

\section{Firms' dynamics}

As illustrated in sections 1 and 2, the analytical solution method adopted by this paper operates through a reduction in the heterogeneity by grouping the agents into clusters. In order to study the stochastic evolution of the system analytically we use a mean-field approximation, which essentially involves reducing the vector of observations of a variable to a single value for a given population (Brock and Durlauf, 2001). In the present

\footnotetext{
${ }^{10}$ The simulations without changes in firms' demography will also permit a consistent comparison with the analytical solution, which does not explicitly consider bankruptcy, in section 5. Figures displaying results for this last scenario were not shown for space constraints but are available upon request.

${ }^{11}$ Last two figures available upon request.
} 
treatment, the mean-field approximation is performed by simply taking the average of the relevant microvariables within each group.

The following step is presented in subsection 4.1 and concerns the definition of the probabilistic rules that determine the switch of firms between groups. The dynamics of the number of agents in each cluster is assumed to follow a Markovian stochastic process. This class of processes can be described by a master equation, namely a stochastic differential equation that depends on the probabilities of transition between states. The main steps of this procedure and the solution of the master equation are presented is subsection 4.2. In particular, this solution can be expressed by an ordinary differential equation plus a stochastic component given by a Wiener process. Both the ordinary differential equation and the noise term are formulated as functions of the microvariables that determine the transition of agents between groups. This result is then used in section 5 for the derivation of the laws of motion of relevant macroeconomic variables.

As for the notation, since the population of firms is reduced to just two (one average hedge firm and one average borrowing firm), the superscript $j$ is no longer used for firm-level variables.

\subsection{Transition probabilities}

The probability of a single firm changing state can be derived using (1) or (2). In particular, a hedge firm turns to speculative if its net profit becomes negative according to condition (1), while a speculative firm becomes hedge if it earns a positive net profit, based on condition (2). The magnitude of each firms' net profit depends on the idiosyncratic shock $s$, which determines the quantity they sell. As the distribution of the shock $s$ is known by assumption, it is convenient to quantify the probabilities of transition as function of $s$. Let us preliminarily define the variable $\Gamma_{z}$ as

$$
\Gamma_{z, t}=\left(\frac{\bar{i}_{t} b_{z, t}}{\Pi p q_{z, t}}-1\right) \frac{K_{t}}{K_{t}-k_{z, t}}
$$

Using equations (1), (2), (7) and (11), it follows that a speculative firm $j$ becomes hedge and hedge firms becomes speculative if, respectively

$$
s_{t}^{j} \geq \Gamma_{1, t} \quad \text { and } \quad s_{t}^{j}<\Gamma_{2, t}
$$

The first probability will be denoted by $\eta$ and the second by $\zeta$. Accordingly, we can write

$$
\eta_{t}^{j}=\operatorname{Pr}\left[s_{t} \geq \Gamma_{1, t}\right] \quad \text { and } \quad \zeta_{t}^{j}=\operatorname{Pr}\left[s_{t}<\Gamma_{2, t}\right]
$$

Assuming $s$ to be uniformly distributed in the interval $[-0.5,0.5]$, we are able to quantify the two probabilities using the cumulative distribution function of $s$, so that:

$$
\begin{gathered}
\eta_{t}=0.5-\Gamma_{1, t} \\
\zeta_{t}=0.5+\Gamma_{2, t}
\end{gathered}
$$

\subsection{Solution to the master equation: stochastic dynamics of trend and fluctuations}

If we assume that the number of firms in each of the two states follows a jump Markov process, we can use the master equation to describe the stochastic evolution of the system. Taking $N_{1}$ as our state variable, the master equation allows us to represent the dynamics of the probability of a certain number of firms $N_{1}$ being in state 1 as the balance equation between the aggregate transition to and from state 1 . Considering an interval of time 
$\Delta t$ small enough to be approximated by a continuous time representation, we can express the master equation for the dynamics of firms in state 1 as

$$
\frac{d P\left(n_{1}, t\right)}{d t}=\eta(t) P\left(n_{1}-1 / N\right)(t)+\zeta(t) P\left(n_{1}+1 / N\right)(t)+[\eta(t)+\zeta(t)] P\left(n_{1}\right)(t)
$$

where $n_{1}=N_{1} / N$.

Equation (23) describes the dynamics of the probability of having a fraction $n_{1}$ of speculative firm as the sum of the probability of transitioning from a number $N_{1}-1$ to $N_{1}$ and the probability of transitioning from a number $N_{1}+1$ to $N_{1}$, less the probability of already having a number $N_{1}$ of speculative firm times the probability of a transition into or from the speculative state. The master equation can be solved using approximation techniques ${ }^{12}$. For this algorithm to be applied, the state variable must be split into trend and cyclical components. Following Aoki (2002) and indicating, respectively, with $\bar{n}_{1}$ the deterministic trend and $v$ the deviation, the state variable can be reformulated as

$$
n_{1}=\phi+N^{-1 / 2} v
$$

so as to normalize the standard deviation $v$.The development of the solution algorithm yields the following ODE for the trend

$$
\dot{\phi}=\zeta \phi-(\eta+\zeta) \phi^{2}
$$

The stationary solution of the second equation presumes a Gaussian distribution for the stochastic noise around the trend, so that:

$$
P(v)=C \exp \left(-\frac{v^{2}}{2 \sigma^{2}}\right)
$$

such that $P(v) \sim \mathscr{N}\left(0, \frac{\eta \zeta}{(\eta+\zeta)^{2}}\right)$ The dynamics of $n_{1}$ can thus be described by

$$
\dot{n}_{1}(t)=\zeta \phi-(\eta+\zeta) \phi^{2}+\sigma d V(t)
$$

where $d V$ is a stationary Wiener increment and $\sigma d V$ is the stochastic fluctuation component in the proportion of speculative firms, coming from the distribution (26).

The solution of the master equation provides a good approximation for the underlying agent-based model despite the reduction in heterogeneity. Figure 3 shows the results for the share of speculative firms, obtained for the master equation solution by using the results of the simulations of the agent based model in equation (27), and the level of aggregate debt obtained from the product of the mean-field values of firms' debt $b_{1}$ and $b_{n}$ and the corresponding number of firms. The proportion $n_{1}$ is weighted by the number of surviving firms, so as to take into account the effect of bankruptcy 13 . Without bankruptcy, the two series move together during expansions while, during recessions, the master equation solution $n_{1}$ does not drop until the cycle is very close to its trough. Having tested the reliability of the analytical solution, we can now use it to gain further insights into the behavior of the model.

\footnotetext{
${ }^{12}$ The solution algorithm introduced by Aoki (2002) and further developed by Landini and Uberti (2008) and Di Guilmi (2008), has the advantage of returning a solution that is composed by two equations: an ordinary differential equation, which describes the time evolution of the trend of the stochastic process, and a partial differential equation (known as Fokker-Planck equation), whose general solution identifies the probability distribution of the fluctuations around the drift component. The full derivation of the solution is omitted here. We refer the interested reader to Di Guilmi (2008) and Chiarella and Di Guilmi (2011).

${ }^{13}$ Di Guilmi et al. (2012) proposes and uses a solution method for the master equation for a system with a variable number of agents. Given the considerable analytical complexity of that treatment and the scope of the present paper we adopted the simplification of considering $N$ fixed and consider this difference in the comparison of the numerical and analytical treatment.
} 


\section{Analytical solution}

This section presents an analytical assessment of the links between debt dynamics at the micro and macro levels. In particular, it highlights the role of firms' heterogeneity for the dynamics of aggregate debt and leverage.

We will thus start by studying separately the evolution of the stock of debt held by speculative and hedge firms, before proceeding to a macro analysis. The results of the analysis are also compared with the outcomes of the Monte Carlo simulations, yielding further insights on the causal relationships determining the dynamics of the model 14

\subsection{Debt dynamics}

In this subsection we focus on the joint dynamics of $b_{1}, b_{2}$ and $N_{1}$, looking first at the steady state values and then at the conditions for stability.

\subsubsection{Steady-state analysis}

Proposition 1. At the steady-state where $\dot{b}_{1}=\dot{b}_{2}=0$, the mean-field debt-to-output ratio of speculative firms is higher than that of hedge firms. Formally: $\frac{\tilde{b_{1}}}{p q_{1}}>\frac{\tilde{b_{2}}}{p q_{2}}$.

Proposition 2. At the equilibrium where $\dot{b}_{1}=\dot{b}_{2}=\dot{N}_{1}=0$, which constitutes a steady-state for the aggregate level of debt $B$, the number of speculative firms $\tilde{N}_{1}$ is the higher, the lower is $\alpha_{1}$, the sensitivity of speculative firms' investment to profits. The direction of the response of $\tilde{N}_{1}$ to parameters $\bar{i}, \alpha_{2}, \beta, \lambda$ and $\Pi$ depends on the specific parametric configuration.

Proposition 3. At the equilibrium where $\dot{b}_{1}=\dot{b}_{2}=\dot{N}_{1}=0$, the steady-state value of aggregate debt $\tilde{B}$ is the higher, the higher is, ceteris paribus, the degree of heterogeneity between the two subgroups of firms as for the sensitivity of investment to profits $\left(\alpha_{1}-\alpha_{2}\right)$, while, for $\alpha_{1}=\alpha_{2}$, it is unaffected by the difference in the magnitude of output, or firms' size, $\left(q_{1}-q_{2}\right)$.

The results of the steady state analysis generally match the outcomes of numerical simulations previously described ${ }^{15}$ In fact, in all the simulations $\frac{b_{1}}{p q_{1}}>\frac{b_{2}}{p q_{2}}$ as for proposition 1 . The analytical approximation of the agent-based model reveals that this regularity is emerging due to behavioral heterogeneity $\left(\alpha_{1}>\alpha_{2}\right)$. Proposition 2 proves that the inverse correlation between $\alpha_{1}$ and $N_{1}$ showed in figure $2 \mathrm{a}$ is independent of the parameter configuration, while the patterns that emerge in the Monte Carlo simulations for $\bar{i}, \beta$ and $\lambda$ have relied on a particular parameter setting. Even with a number of different Monte Carlo simulations using different parameter settings, the full reliance on numerical solutions would not be sufficient to provide this kind of certainty. Finally, given that $\alpha_{2}$ is constant in the Monte Carlo simulations, Proposition 3 illustrates the causal relationship through which the model generates the direct correlation between $\alpha_{1}$ and aggregate debt displayed by figure $2 \mathrm{a}$. The second statement of proposition 3 stresses the role of behavioral heterogeneity relative to size heterogeneity for the outcome of the simulations. Again, this is a result that could not be achieved with the sole numerical analysis, given the impossibility of forcing size homogeneity across firms.

Summing up, the level of heterogeneity in the elasticity of the investment function to internal finance appears to be crucial for the long run dynamics of the economy. For a given level of $\alpha_{2}$, a larger $\alpha_{1}$ implies not only a larger difference in the leverage ratio of the two types of firms but also a greater stock of aggregate debt. Speculative firms invest more and, consequently, resort to credit. At the same time, a larger $\alpha_{1}$ reduces the steady-state level of the number of speculative firms. Given that $B=N_{1} b_{1}+N_{2} b_{2}$, the effect is larger on

\footnotetext{
${ }^{14}$ Proofs are sketched in the appendix. Complete proofs are available upon request.

${ }^{15}$ In the present analysis, we consider the outcome of the Monte Carlo simulations as an approximation of the steady state.
} 
$b_{1}$ than on $N_{1}$. The decrease in $N_{1}$ can be explained from the fact that speculative firms rely more on internal finance for capital accumulation, which also raises their chances of becoming hedge.

\subsubsection{Stability analysis}

In this subsection we will focus on the joint stability of $b_{1}$ and $N_{1}$ around the steady-state, given the more crucial role of speculative firms' leverage for the financial stability of the system as a whole, from a Minskyan standpoint. A stability analysis for hedge firms, or $b_{2}$ and $N_{2}$, can be derived in similar fashion. This study provides additional qualitative insights on the results of the Monte Carlo simulations.

The analysis will be based on the system of differential equations composed by expressions (37) and (34).

Proposition 4. The interest rate $\bar{i}$ has an ambiguous effect on the stability of the dynamical system ${ }^{16}$

The uncertainty about the effect of the interest rate is a consequence of the different role it has on the dynamics of the number of speculative firms and on their individual level of debt. On the one hand, a higher interest rate increases the number of speculative firms through its effect profits in equation (11). Due to the logistic functional form of the dynamics of speculative firms (27), as the level of $N_{1}$ increases, its rate of growth decelerates, such that $\frac{\partial \dot{N}_{1}}{\partial N_{1}}<0$. On the other hand, the interest rate positively affects $\dot{b}_{1}$, through its negative effect on retained profits. As a consequence $\frac{\partial \dot{b}_{1}}{\partial b_{1}}$ responds positively to $\bar{i}$. The two effects are embodied in the expression for the trace of the system's Jacobian matrix, as analyzed below.

Proof. After deriving the Jacobian of the system $\left(\dot{N}_{1}, \dot{b}_{1}\right)$ from expressions $(37)$ and $(34)$ and evaluating it at the steady-state, the trace of $J$ is thus given by:

$$
\operatorname{Tr}(J)=0.5-\frac{\bar{i}}{\Pi} \frac{b_{2}}{p q_{2}}-(\lambda-\bar{i})
$$

By further substituting for the steady-state of $b_{2}$ from (36), we have that in the vicinity of the steady-state for total debt $B$ analyzed in the previous subsection, the trace is:

$$
\operatorname{Tr}(J)=0.5-\frac{\bar{i}}{\Pi} \frac{\left(\alpha_{2}-1\right) \Pi+\beta}{\lambda-\bar{i}}-(\lambda-\bar{i})
$$

The system is hence unstable whenever the following expression holds:

$$
\frac{\bar{i}}{\Pi} \frac{\left(\alpha_{2}-1\right) \Pi+\beta}{\lambda-\bar{i}}+(\lambda-\bar{i})>0.5
$$

Debt instability for speculative firms is thus more likely when the profit share $\Pi$ is high, and the response of hedge firms' investment to profits and demand, $\alpha_{2}$ and $\beta$, respectively, are low. The effect of the interest rate on debt stability depends on parameter configurations.

Proposition 5. Given the constraints on the parameters, the steady states for $\dot{b}_{1}$ and $\dot{N}_{1}$ are most likely on a saddle path.

\footnotetext{
${ }^{16} \mathrm{We}$ numerically assess the effect of the interest rate on the stability of the system for the following values and ranges of parameters: $\alpha_{2}=0.2, \beta=0.5, \lambda \in[0.15,0.35], \Pi \in[0.3,0.5], \bar{i} \in[0.05,0.1]$. The stabilizing effect coming from a lower $\dot{N}_{1}$ appears to dominate the destabilizing effect of an increase in the average debt of speculative firms, such that a larger interest rate makes a stable trajectory more likely. In particular, as shown by figure $4 \mathrm{a}$, for $\lambda=0.15, \bar{i}>0.8, \Pi=0.5$ the determinant becomes positive. A lower $\lambda$ increases $N_{1}$, thus reducing $\dot{N}_{1}$, due to the logistic functional form of 27 . Figure $4 b$ illustrates that the determinant is also more likely to be positive for low values of $\Pi$. In particular we verified it is always positive for $\lambda=0.35, \bar{i}>0.5, \Pi=0.3$. Thus, a higher profit share negatively affects the stability of the system $\dot{N}_{1}, \dot{b}_{1}$.
} 
Proof. After a few algebraic simplifications, the determinant of $\mathrm{J}$ can be written as:

$$
\operatorname{Det}(J)=\bar{i}\left(\alpha_{2}-1+\frac{\beta}{\Pi}\right)-\frac{(\lambda-\bar{i})}{2 \Pi}
$$

The case of saddle-path (in)stability is thus obtained whenever the interest rate is sufficiently low ${ }^{17}$ and the term in the right and side of expression (29), which increases with the sensitivity of investment to debt $\lambda$, and decreases with the profit share $\Pi$, the sensitivity of hedge firms' investment to profits $\alpha_{2}$, and the response of investment to output, $\beta$.

$$
\bar{i}<\frac{\lambda}{2 \Pi\left(\alpha_{2}-1\right)+2 \beta+1}
$$

Propositions 4 and 5 complete the study of the sensitivity of the system to parameters, identifying ranges of stability. Again, a numerical approach could only lead to this type of interpretation through multiple attempts, by reporting for example the values of the parameters for which the simulation crashes or returns inconsistent results, without any possibility of generalization.

\subsection{Dynamics of capital and the leverage ratio}

With $0<\delta<1$ as the rate of capital depreciation and investment from (19), the law of motion for speculative firm's capital stock $\dot{k}_{1}$, in value, can be expressed as:

$$
p \dot{k}_{1}(t)=\left(\alpha_{1} \Pi+\beta\right) p q_{1}(t)-\lambda b_{1}(t)-p \delta k_{1}(t)
$$

Consequently, $k_{1}$ reaches the steady state at:

$$
p \tilde{k}_{1}=\frac{\left(\alpha_{1} \Pi+\beta\right) p q_{1}-\lambda b_{1}}{\delta}
$$

Proposition 6. At the steady-state for both $b_{1}$ and $k_{1}$, the leverage ratio for the speculative firm, $\tilde{b}_{1} /\left(p \tilde{k}_{1}\right)$, is the higher, (i) the higher is the interest rate $\bar{i}$, (ii) the higher is the depreciation rate $\delta$, (iii) the lower is the sensitivity of investment to leverage $\lambda$, (iv) the higher is the sensitivity of investment to profits $\alpha_{1},(v)$ the higher is the sensitivity of investment to output $\beta$, and (vi) the lower is the profit share $\Pi$.

Proof. By expressing $p q_{1}$ as a function of $\tilde{b}_{1}$ and substituting in 31 , we obtain the steady-state leverage ratio for the speculative firm 18 .

$$
\frac{\tilde{b}_{1}}{p \tilde{k}_{1}}=\frac{\delta\left(\alpha_{1}+\beta / \Pi-1\right)}{\lambda-\bar{i}\left(\alpha_{1}+\beta / \Pi\right)}
$$

Proposition 7. At the steady-state for $b_{1}, b_{2}, k_{1}$ and $k_{2}$, the leverage ratio of speculative firms is higher than that of hedge firms. Formally:

$$
\frac{\tilde{b}_{1}}{p \tilde{k}_{1}}>\frac{\tilde{b}_{2}}{p \tilde{k}_{2}}
$$

\footnotetext{
${ }^{17}$ In the benchmark scenario of the simulations the interest rate is in the stability range, not satisfying conditions 28 and 29 .

${ }^{18}$ Proposition 6 also expresses some of the results of the Monte Carlo simulation, and demonstrates that these outcomes do not rely on specific parameter configurations. Given that the analytical solution does not consider bankruptcy of firms, the relevant plot for this comparison is not the one showed in the appendix.
} 
Proof. Analogously, the steady-state leverage ratio for hedge firms is given by:

$$
\frac{\tilde{b}_{2}}{p \tilde{k}_{2}}=\frac{\delta\left(\alpha_{2}+\beta / \Pi-1\right)}{\lambda-\bar{i}\left(\alpha_{2}+\beta / \Pi\right)}
$$

Proposition 7 hence follows from comparing equation (32) to (33), on the assumption that $\alpha_{1}>\alpha_{2}$.

Proposition 8. At the steady-state where $\dot{k}_{1}=\dot{k}_{2}=\dot{b}_{1}=\dot{b}_{2}=\dot{N}_{1}=0$, the steady-state level of aggregate capital stock $\tilde{K}$ decreases with firms' heterogeneity in the sensitivity of investment to profits $\left(\alpha_{1}-\alpha_{2}\right)$, but is unaffected by the heterogeneity in firms' size $\left(q_{1}-q_{2}\right)$.

Proposition 8 integrates the results of the Monte Carlo simulations by separately studying the role of heterogeneity in, respectively, behavior and size, and confirm the stronger relevance of the former in shaping the long-run dynamics of the system. Interestingly, results for $\alpha_{1}-\alpha_{2}$ are not consistent with the numerical simulations, which implies that the result of proposition 8 cannot be generalized to the case in which heterogeneity in size is present. From this perspective the Monte Carlo simulations and the analytical solution can be seen as complementary for the understanding of the role of heterogeneity.

Proposition 9. At the steady-state where $\dot{k}_{1}=\dot{k}_{2}=\dot{b}_{1}=\dot{b}_{2}=\dot{N}_{1}=0$, the aggregate leverage ratio $\tilde{B} /(p \tilde{K})$ is the higher, (i) the higher is the interest rate $\bar{i}$, (ii) the lower is the response of investment to debt $\lambda$, and (iii) the higher is the degree of heterogeneity in the response of investment to profits $\alpha_{1}-\alpha_{2}$, while it is unaffected by the heterogeneity in firms' size $q_{1}-q_{2}$.

Given $\alpha_{2}$, a higher $\alpha_{1}$ reduces the accumulation of capital and, consistently with the results of proposition 3 , increases the aggregate leverage ratio. This is a consequence of the larger reliance of capital accumulation on the less financially sound firms. Proposition 9 confirms the results of the Monte Carlo simulations for $\alpha_{1}$ and $\bar{i}$, which do not depend on the parameter configuration. The analysis points to the role of behavioral variables, and in particular to the sensitivity of investment to internal finance and debt, as the key drivers of the system along a more sustainable long-run path. The statements of proposition 9 are consistent with figures $2 \mathrm{a}$, 2b and ??, thus suggesting that point (iii) of the proposition holds also with size heterogeneity.

The results of this subsection, when taken together with the stability analysis of the system, help illuminate the implications of the Monte Carlo simulations for the role of the interest rate. It becomes clear that the handling of the interest rate $\bar{i}$ can have perverse effects on the system dynamics by accelerating the accumulation of debt and, over a certain threshold, can lead the system to instability. Consequently, a lean-against-the-wind policy can add to the fragility of the system and does not represent an ideal tool to halt a speculative boom.

\section{Concluding remarks}

This paper introduces microeconomic foundations into a demand-driven macroeconomic model in order to study the role of real-financial linkages in generating economic growth and business cycles endogenously. The paper shows that the analysis of systemic financial fragility is greatly enriched by the introduction of heterogeneous microeconomic behavior, in line with Minky's approach. To this aim, the model was initially built in a bottom-up fashion and solved numerically with full heterogeneity of agents. An aggregation method imported from statistical mechanics then helped us reduce the degree of heterogeneity between firms to only two classes - inspired by Minsky's terminology of hedge and speculative financial behavior - thus allowing for the study of the relationship between micro behavioral rules and macroeconomic dynamics of firms' leverage and capital.

The analytical study has added to the results of the numerical simulations in at least four different ways. First, it demonstrates which results from the Monte Carlo simulations can be generalized, and which ones rely 
on particular parametric configurations. Second, it illuminates the causal relationships that lead to the observed effects of changing parameters on the macro variables in the simulations. Third, it allowed for a systematic study of stability conditions that cannot be performed in non-trivial agent-based models. Fourth, it permits experiments that are not possible in simple numerical simulations, such as examining the role of heterogeneity of agents along a specific dimension, while keeping other dimensions homogenous. The analytical representation of the stability conditions and causal chain within the model can also assist in the calibration the numerical simulations, by identifying parameter ranges in which the model is unstable or yields inconsistent results.

With reference to the specific results of this model, the analysis shows that a higher difference in the response of firms' investment to internal finance between speculative and hedge firms pushes the system along a long-run path characterized by higher leverage and lower capital accumulation. In fact, a larger difference $\alpha_{1}-\alpha_{2}$ implies that growth relies more on speculative firms and therefore on borrowing. In terms of policy indications, the analysis shows that a higher interest rate on loans is likely to have a stabilizing role, but at the price of a higher share of speculative firms with a high leverage ratio in the economy. It is worth noting that a higher sensitivity of speculative firms to internal finance leads, ceteris paribus, to a larger accumulation of debt at micro and macro-level. The increase in external financing appears to offset the benefit of a more conservative attitude of speculative firms. In terms of income distribution, a larger share of profit has a potentially destabilizing effect on the dynamics of the system.

The integration of Monte Carlo simulations with the analysis of the dynamical system derived from this analytical approximation of the agent-based model represents an absolute primer in the literature, and we hope that it will pave the way for a different modeling approach. While at this stage of developments, numerical simulations are still essential for a complete analysis of model outcomes, especially due to nonlinearities in the system, the proposed analytical solution provides a benchmark for interpreting and generalizing these results. Besides the introduction of a multi-state master equation, which can provide a more accurate approximation of the underlying agent-based model, a possible further development concerns a more refined study of the conditions under which bubbles and busts are generated in the present setting. When it comes to adding more realistic features to the model setup, possible extensions include, for instance, incorporating a stock market, endogenizing the mark-up rate and the functional distribution of income, as well as allowing for heterogeneity in the household and/or financial sector.

\section{References}

AOKI, M. (2002): Modeling aggregate behaviour and fluctuations in economics., Cambridge University Press.

Aoki, M. and YoshiKawa, H. (2006): Reconstructing Macroeconomics, Cambridge University Press.

Bezemer, D. J. (2010): Understanding Financial Crisis Through Accounting Models, Accounting, Organizations and Society, 35(7): pp. $676-688$.

Brock, W. A. and Durlauf, S. N. (2001): Discrete Choice with Social Interactions, Review of Economic Studies, 68(2): pp. 235-60.

Chiarella, C. and Di Guilmi, C. (2011): The Financial Instability Hypothesis: A Stochastic Microfoundation Framework, Journal of Economic Dynamics and Control, 35(8): pp. 1151 - 1171.

Delli Gatti, D., Di Guilmi, C., Gaffeo, E., Giulioni, G., Gallegati, M. and Palestrini, A. (2005): A New Approach to Business Fluctuations: Heterogeneous Interacting Agents, Scaling Laws and Financial Fragility, Journal of Economic Behavior and Organization, 56(4): pp. 489-512. 
Delli Gatti, D., Gaffeo, E. and Gallegati, M. (2010): Complex Agent-Based Macroeconomics: a Manifesto for a New Paradigm, Journal of Economic Interaction and Coordination, 5: pp. 111-135, 10.1007/s11403-010-0064-8.

Delli Gatti, D., Gallegati, M. and Gardini, L. (1993): Investment Confidence, Corporate Debt and Income Fluctuations, Journal of Economic Behavior \& Organization, 22(2): pp. 161-187.

Di GuILMi, C. (2008): The generation of business fluctuations: financial fragility and mean-field interaction, Peter Lang Publishing Group: Frankfurt/M.

Di Guilmi, C., Gaffeo, E., Gallegati, M. and Palestrini, A. (2005): International Evidence on Business Cycle Magnitude Dependence: An Analysis of 16 Industrialized Countries, 1881-2000, International Journal of Applied Econometrics and Quantitative Studies, Euro-American Association of Economic Development, 2(1): pp. 5-16.

Di Guilmi, C., Gallegati, M., LAndini, S. and Stiglitz, J. E. (2012): Dynamic Aggregation of Heterogeneous Interacting Agents and Network: An Analytical Solution for Agent Based Models, Tech. rep., mimeo, URL http://www2.gsb.columbia.edu/faculty/jstiglitz/topics.cfm.

Dos SAntos, C. H. (2005): A Stock-Flow Consistent General Framework for Formal Minskyan Analyses of Closed Economies, Journal of Post Keynesian Economics, 27(4): pp. 712-735.

Dosi, G., Fagiolo, G., Napoletano, M. and Roventini, A. (2013): Income distribution, credit and fiscal policies in an agent-based Keynesian model, Journal of Economic Dynamics and Control, 37(8): pp. $1598-1625$.

DutT, A. K. (1984): Stagnation, income distribution and monopoly power, Cambridge Journal of Economics, 8(1): pp. 25-40.

Fazzari, S. M., Hubbard, G. and Petersen, B. C. (1988): Financing Costraints and Corporate Investments, Brookings Papers on Economic Activity, (1): pp. 141-195.

FolEy, D. K. (1994): A Statistical Equilibrium Theory of Markets, Journal of Economic Theory, 62(2): pp. $321-345$.

Godin, A. and Kinsella, S. (2012): Leverage, liquidity and crisis: A simulation study, ASSRU Discussion Papers 1205, ASSRU - Algorithmic Social Science Research Unit.

Godley, W. and LAVOIE, M. (2007): Monetary Economics: an integrated approach to credit, money, income, production and wealth, Palgrave Macmillan: London.

KAleCKi, M. (1971): Selected Essays on the Dynamics of the Capitalist Economy, Cambridge University Press.

Khalil, S. and Kinsella, S. (2011): Bad Banks Choking Good Banks: a Simulating Balance Sheet Contagion, Working Papers 201126, Geary Institute, University College Dublin.

KIM, Y. and ISAAC, A. (2010): The Macrodyamics of Household Debt, Working Papers 1010, Trinity College, Department of Economics.

LAndini, S. and Uberti, M. (2008): A Statistical Mechanics View of Macro-dynamics in Economics, Computational Economics, 32(1): pp. 121-146. 
MinsKy, H. P. (2008): John Maynard Keynes, McGraw-Hill, first edition 1975.

Rowthorn, R. (1982): Demand, Real Wages and Economic Growth, Studi Economici, 18: pp. 3-53.

Schularick, M. and TAYlor, A. M. (2012): Credit Booms Gone Bust: Monetary Policy, Leverage Cycles, and Financial Crises, 1870-2008, American Economic Review, 102(2): pp. 1029-61.

TAYlor, L. (1985): A Stagnationist Model of Economic Growth, Cambridge Journal of Economics, 9(4): pp. 383-403.

TAYlor, L. and O'Connell, S. A. (1985): A Minsky Crisis, The Quarterly Journal of Economics, 100(5): pp. 871-85.

ToBin, J. (1969): A General Equilibrium Approach to Monetary Theory, Journal of Money, Credit and Banking, 1(1): pp. 15-29.

VAn Treeck, T. (2009): A Synthetic, Stock-Flow Consistent Macroeconomic Model of 'Financialisation', Cambridge Journal of Economics, 33: pp. 467-493.

Weidlich, W. (2000): Sociodynamics: A Systematic Approach to Mathematical Modelling in the Social Sciences, Gordon and Breach: London.

\section{A Sketch of the proofs.}

Proof of Proposition 1. Using the law of motion (12) and substituting for $i$ and $a$ from (3) and (11), the evolution of the mean-field level of debt for speculative firms is given by

$$
\dot{b}_{1}(t)=\left[\left(\alpha_{1}-1\right) \Pi+\beta\right] p q_{1}(t)-(\lambda-\bar{i}) b_{1}(t)
$$

At the steady-state, the debt-to-output ratio for speculative firms is thus:

$$
\left(\frac{\tilde{b_{1}}}{p q_{1}}\right)=\frac{\left(\alpha_{1}-1\right) \Pi+\beta}{\lambda-\bar{i}}
$$

Analogously, for hedge firms, the steady-state value for the debt-to-output ratio is given by 19 .

$$
\left(\frac{\tilde{b_{2}}}{p q_{2}}\right)=\frac{\left(\alpha_{2}-1\right) \Pi+\beta}{\lambda-\bar{i}}
$$

Since we have considered that speculative firms are more sensitive than hedge firms to their profit rate when deciding to invest, namely that $\alpha_{1}>\alpha_{2}$, the equilibrium debt-to-output ratio is also higher for the former category.

Proof of Proposition 2. Using the law of motion for the number of speculative firms 27 and substituting for $\eta$ and $\zeta$ using expressions (21), 22) and (20), we get:

$$
\dot{N}_{1}(t)=N\left\{\left(-0.5+\frac{\bar{i}}{\Pi} \frac{b_{2}(t)}{p q_{2}(t)}\right) N_{1}(t)-\left[1+\frac{\bar{i}}{\Pi}\left(\frac{b_{2}(t)}{p q_{2}(t)}+\frac{b_{1}(t)}{p q_{1}(t)}\right)\right] N_{1}(t)^{2}\right\}
$$

\footnotetext{
${ }^{19}$ The correspondence between the two cases only holds because the steady-state value for hedge firms for which debt evolved according to the alternative law of motion $\sqrt{13}$ p is zero.

${ }^{20}$ The stochastic noise is not considered in the present analysis since its expected value is null. The term $\frac{K_{t}}{K_{t}-k_{z, t}}$ that appears in equation 20, can be considered equal to 1 for a large number of firms $N$ and can be thus be omitted.
} 
The number of speculative firms is constant when $\dot{N}_{1}=0$, which yields the steady-state, already using $(35)$ and (36):

$$
\tilde{N}_{1}=N \frac{-\frac{\lambda}{2}+\bar{i}\left(\alpha_{2}+\frac{\beta}{\Pi}-\frac{1}{2}\right)}{\lambda+\bar{i}\left(\alpha_{2}+\alpha_{1}+2 \frac{\beta}{\Pi}-3\right)}
$$

The number for speculative firms hence depends ambiguously on the interest rate on loans and the debt-tooutput ratios of hedge firms, while it decreases with the level of the debt-to-output ratio of speculative firms. As the total number of firms $N$ is fixed, the steady-state value for the number of hedge firms is $\tilde{N}_{2}=N-\tilde{N}_{1}$. Hence, in the equilibrium where $N_{1}, b_{1}$ and $b_{2}$ are constant, the total stock of firms' debt $B$ is also constant ${ }^{21}$.

\section{Proof of Proposition 3.}

$$
\tilde{B}=\tilde{N}_{1} \tilde{b}_{1}+\left(N-\tilde{N}_{1}\right) \tilde{b}_{2}=\tilde{N}_{1}\left(\tilde{b}_{1}-\tilde{b}_{2}\right)+N \tilde{b_{2}}
$$

By substituting $\tilde{b}_{1}$ and $\tilde{b}_{2}$ :

$$
\tilde{B}=\frac{\Pi p}{\lambda-\bar{i}}\left[\tilde{N}_{1}\left[\left(\alpha_{1} q_{1}-\alpha_{2} q_{2}\right)+(\beta / \Pi-1)\left(q_{1}-q_{2}\right)\right]+N\left(\alpha_{2}-1+\beta / \Pi\right) q_{2}\right]
$$

where $\tilde{N}_{1}$ is only as a function of parameters, as expressed in 38 .

From (39), the steady-state value of aggregate debt in the special case of full homogeneity between subgroups of firms in both (i) the sensitivity of investment to profits ( $\left.\alpha=\alpha_{1}=\alpha_{2}\right)$, and (ii) firms' size $\left(k=k_{1}=k_{2}\right)$, which from (6) and (7) is equivalent to assuming the same output $q=q_{1}=q_{2}$, would be given by:

$$
\tilde{B}(\alpha, q)=\frac{[(\alpha-1) \Pi+\beta] p Q}{\lambda-\bar{i}}
$$

Assuming that firms have the same sensitivity of investment to profits $\left(\alpha=\alpha_{1}=\alpha_{2}\right.$ ), but are heterogeneous in size $\left(q_{1} \neq q_{2}\right)$, and, respectively, assuming that firms have the same size $\left(q=q_{1}=q_{2}\right)$ but are heterogeneous in the sensitivity of investment to profits $\left(\alpha_{1} \neq \alpha_{2}\right)$, we get:

$$
\tilde{B}\left(\alpha, q_{1}, q_{2}\right)=\frac{[(\alpha-1) \Pi+\beta] p Q}{\lambda-\bar{i}}=\tilde{B}(\alpha, q) \quad \text { and } \quad \tilde{B}\left(\alpha_{1}, \alpha_{2}, q\right)=\tilde{B}(\alpha, q)+\frac{\tilde{N}_{1} \Pi p q\left(\alpha_{1}-\alpha_{2}\right)}{\lambda-\bar{i}}
$$

It is thus clear that the higher is heterogeneity in investment behavior, namely the higher is $\alpha_{1}$ relative to $\alpha_{2}$, the higher is aggregate debt.

Proof of Proposition 8. The aggregate level of capital $K$ reaches a steady-state level $\tilde{K}$ given by:

$$
\tilde{K}=\tilde{N}_{1}\left(\tilde{k}_{1}-\tilde{k}_{2}\right)+N \tilde{k}_{2}
$$

By substituting $\tilde{k}_{1}, \tilde{b}_{1}$ and $\tilde{k}_{2}$ and $\tilde{b}_{2}$ from the analogous expressions for hedge firms, we obtain:

- Full homogeneity: if $q=q_{1}=q_{2}$ and $\alpha=\alpha_{1}=\alpha_{2}$.

$$
\tilde{K}(\alpha, q)=\frac{\Pi}{\delta(\lambda-\bar{i})}\left[\lambda-\bar{i}\left(\alpha+\frac{\beta}{\Pi}\right)\right] N q=\frac{\Pi}{\delta(\lambda-\bar{i})}\left[\lambda-\bar{i}\left(\alpha+\frac{\beta}{\Pi}\right)\right] Q
$$

Hence, in the scenario of full homogeneity, the aggregate output-to-capital ratio $U=Q / \tilde{K}$, which as previously mentioned can be interpreted as a proxy for the firms' degree of capacity utilization, would respond positively to the sensitivity of investment to both profits $(\alpha)$ and output $(\beta)$.

\footnotetext{
${ }^{21}$ This is only a sufficient, not a necessary condition, as $\dot{B}=N_{1} \dot{b}_{1}+\dot{N}_{1} b_{1}+N_{2} \dot{b}_{2}+\dot{N}_{2} b_{2}$.
} 
- Homogeneity in investment behavior: if $q_{1} \neq q_{2}$ and $\alpha=\alpha_{1}=\alpha_{2}$.

$$
\tilde{K}\left(\alpha, q_{1}, q_{2}\right)=\frac{\Pi}{\delta(\lambda-\bar{i})}\left[\lambda-\bar{i}\left(\alpha+\frac{\beta}{\Pi}\right)\right] Q=\tilde{K}(\alpha, q)
$$

- Homogeneity in investment size: if $q=q_{1}=q_{2}$ and $\alpha_{1} \neq \alpha_{2}$.

$$
\tilde{K}\left(\alpha_{1}, \alpha_{2}, q\right)=\frac{\Pi}{\delta(\lambda-\bar{i})}\left\{\tilde{N}_{1}\left[-\bar{i} q\left(\alpha_{1}-\alpha_{2}\right)\right]+\left[\lambda-\bar{i}\left(\alpha_{2}+\frac{\beta}{\Pi}\right)\right] Q\right\}
$$

Proof of Proposition 9. Proposition 9 is a corollary of Propositions 3 and 8 . The equilibrium aggregate leverage ratio is given by:

$$
\frac{\tilde{B}}{p \tilde{K}}=\frac{\delta\left[\tilde{N}_{1}\left[\left(\alpha_{1} q_{1}-\alpha_{2} q_{2}\right)+(\beta / \Pi-1)\left(q_{1}-q_{2}\right)\right]+N\left(\alpha_{2}-1+\beta / \Pi\right) q_{2}\right]}{\tilde{N}_{1}\left[\left(\lambda-\bar{i} \frac{\beta}{\Pi}\right)\left(q_{1}-q_{2}\right)-\bar{i}\left(\alpha_{1} q_{1}-\alpha_{2} q_{2}\right)\right]+N\left[\lambda-\bar{i}\left(\alpha_{2}+\frac{\beta}{\Pi}\right)\right] q_{2}}
$$

- Full homogeneity: if $q=q_{1}=q_{2}$ and $\alpha=\alpha_{1}=\alpha_{2}$.

$$
\frac{\tilde{B}}{p \tilde{K}}(\alpha, q)=\frac{\delta\left[\left(\alpha+\frac{\beta}{\Pi}-1\right)\right]}{\lambda-\bar{i}\left(\alpha+\frac{\beta}{\Pi}\right)}
$$

- Homogeneity in investment behavior: if $q_{1} \neq q_{2}$ and $\alpha=\alpha_{1}=\alpha_{2}$.

$$
\frac{\tilde{B}}{p \tilde{K}}\left(\alpha, q_{1}, q_{2}\right)=\frac{\tilde{B}}{p \tilde{K}}(\alpha, q)
$$

- Homogeneity in size: if $q=q_{1}=q_{2}$ and $\alpha_{1} \neq \alpha_{2}$.

$$
\frac{\tilde{B}}{p \tilde{K}}\left(\alpha_{1}, \alpha_{2}, q\right)=\frac{\delta\left[\tilde{N}_{1} q\left(\alpha_{1}-\alpha_{2}\right)+\left(\alpha_{2}+\frac{\beta}{\Pi}-1\right) Q\right]}{\tilde{N}_{1}\left[-\bar{i} q\left(\alpha_{1}-\alpha_{2}\right)\right]+\left[\lambda-\bar{i}\left(\alpha_{2}+\frac{\beta}{\Pi}-1\right)\right] Q}
$$

Hence, the higher is $\left(\alpha_{1}-\alpha_{2}\right)$, the higher is the numerator and the lower is the denominator of the expression above.
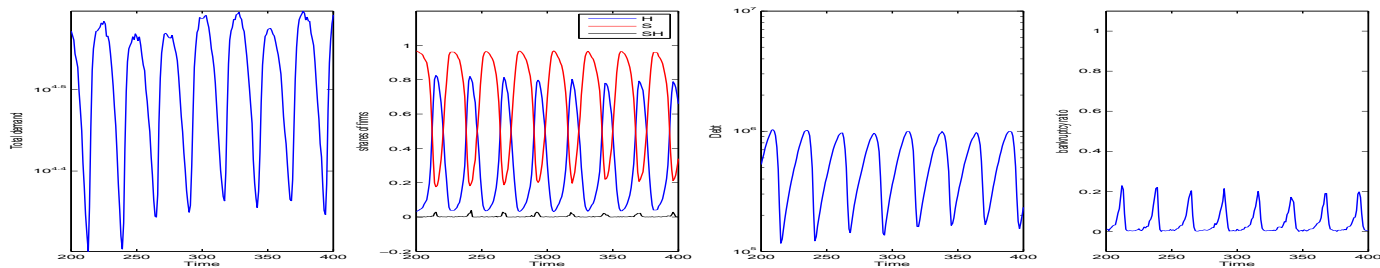

Figure 1: Single run results: aggregate demand, proportion of firms, debt and bankruptcy ratio. 

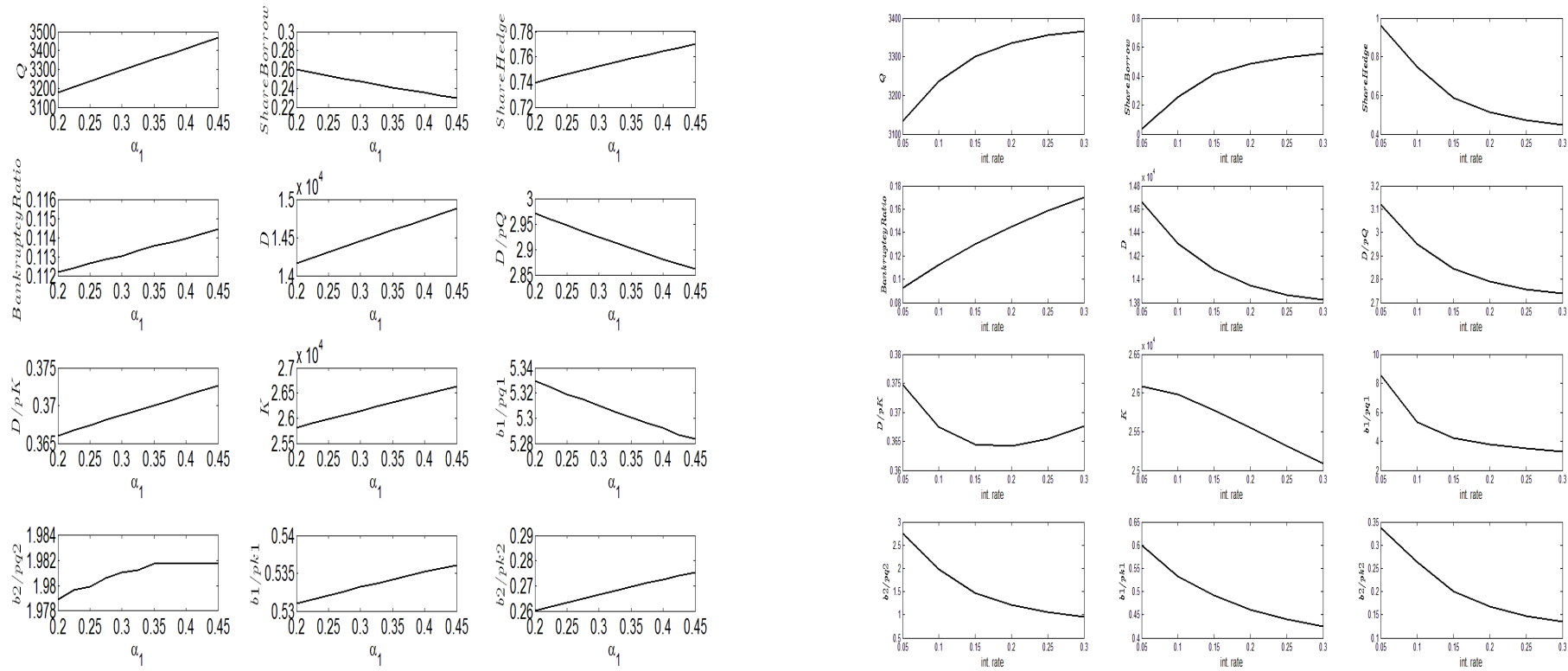

(a) Simulations for $\alpha_{1}$.

(b) Simulations for $\bar{i}$.

Figure 2: Results of Monte Carlo simulations.
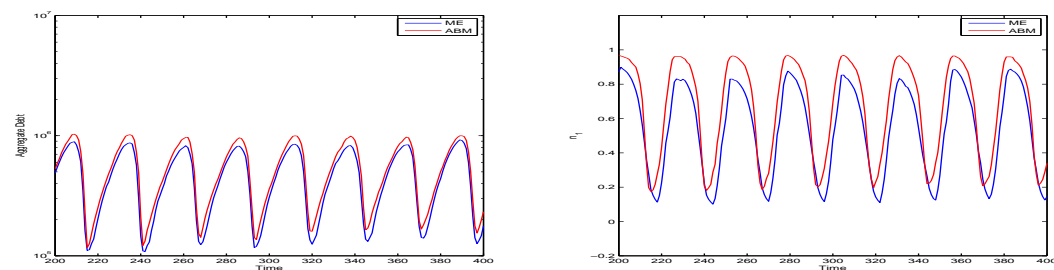

Figure 3: Comparison of the results of the agent-based model and the analytical solution for aggregate debt (upper panel) and share of speculative firms (lower panel).

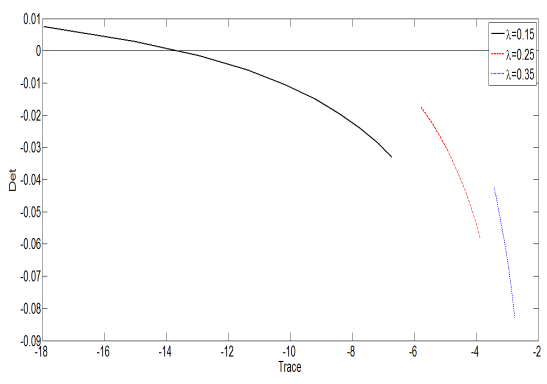

(a) Trace and determinant for different values of $\lambda$ and $\bar{i}$.

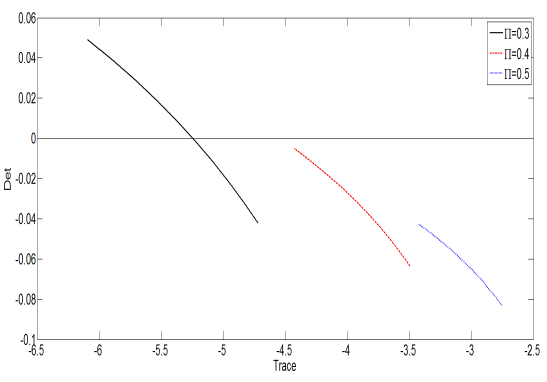

(b) Trace and determinant for different values of $\Pi$ and $\bar{i}$.

Figure 4: Trace and determinant. The interest rate varies from 0.01 to 0.1 as we move north along each contour. 